\section{Relationships between Postharvest Water Loss and Physical Properties of Pepper Fruit (Capsicum annuum L.)}

\author{
N.K. Lownds, M. Banaras, and P.W. Bosland \\ Department of Agronomy and Horticulture, New Mexico State University, Las \\ Cruces, NM 88003
}

Additional index words. cuticle, epicuticular wax

Abstract. Physical characteristics [initial water content, surface area, surface area: volume (SA : V) ratio, cuticle weight, epicuticular wax content, and surface morphology] were examined to determine relationships between physical properties and water-loss 'rate in pepper fruits. 'Keystone', 'NuMex R Naky', and 'Santa Fe Grande' peppers, differing in physical characteristics, were stored at 8,14 , or 20C. Water-loss rate increased linearly with storage time at each temperature and was different for each cultivar. Water-loss rate was positively correlated with initial water content at 14 and $20 \mathrm{C}, \mathrm{SA}: \mathrm{V}$ ratio at all temperatures, and cuticle thickness at 14 and 20C. Water-loss rate was negatively correlated with surface area and epicuticular wax content at all temperatures. Stomata were absent on the fruit surface, and epicuticular wax was amorphous for each cultivar.

Postharvest fruit quality rapidly decreases due to water loss (Ryan and Lipton, 1972; Showalter, 1973; Watada et al., 1987), which limits shipping of New Mexican-type peppers. Studies show pepper varieties, e.g., bell, jalapeño, New Mexican, differ in water-loss rate during storage (Lownds and Bosland, 1988). To our knowledge, the basis for these differences has not been studied.

Fruit physical properties, including initial water content, surface area, surface area : volume (SA : V) ratio, and surface morphology, may affect water loss in horticultural crops (Albrigo, 1972; Ben-Yehoshua, 1987; Robinson et al., 1975; Wills et al., 1981 b), including peppers (Albrigo, 1972; Wills et al., 198 la). Fruits, as with other aerial plant parts, are covered with a cuticle composed of biopolymer cutin and embedded wax, with epicuticular waxes on the outer surface. The cuticle serves as the major barrier to moisture loss (Kolattukudy, 1980; Schonhem, 1976). Therefore, differences in pepper fruit surface morphology and/or epicuticular waxes may affect water-loss rates and postharvest longevity.

In this paper we report on the relationships between physical and morphological properties of pepper fruits and water-loss rates for 'Keystone', 'NuMex R Naky', and 'Santa Fe Grande' peppers during storage. Understanding such relationships may help improve methods of storing and transporting peppers.

Fresh, mature fruits were harvested from 'Keystone' (bell type), 'NuMex R Naky' (New Mexican type), and 'SantaFe Grande' (yellow

Receivedfor publication 8 Mar. 1993. Accepted for publication 2 July 1993. This research was supported bytheNewMexico Agricultural Experiment Station. The cost of publishing this paper was defrayedinpartbythe payment of page charges. Under postal regulations, this paper therefore must be herebymarked advertisement solelytoindicate this fact. wax type) plants grown under standard cultural practices at Leyendecker Plant Science Research Center, Las Cruces, N.M. (Bosland et al., 1991). Fruits without visible defects were hand-picked, placed in plastic bags, and taken to the laboratory.

Postharvest water loss was determined using two 'Keystone' and 'NuMex R Naky' fruits and five 'Santa Fe Grande' fruits per replication. Fruits were weighed and stored unpackaged in growth chambers at 8,14 , and $20 \mathrm{C}$ and $75 \%$ relative humidity, which resulted in vapor pressure deficits (VPD) of $0.21,0.32$, and $0.47 \mathrm{kpa}$, respectively. Fruit weight was recorded every $24 \mathrm{~h}$ for 14 days, and data was expressed as daily percent weight loss. Each cultivar was replicated three times, and the experiment was repeated.

Fruit surface morphology was examined using fruit disks $(0.5 \mathrm{~cm}$ in diameter). Disks were frozen in liquid $\mathrm{N}$, dried $48 \mathrm{~h}$ in a lyophilizer, mounted on aluminum stubs using silver paint, and coated with 60/40 gold-palladium alloy. Five to six randomly selected samples of each cultivar were observed with a Phillips (Phillips Co., Mahwah, N. J.) 501B scanning electron microscope (SEM). Scan14 days.

${ }^{y} P \leq 0.001$ in all cases. ning electron micrographs were taken on Polaroid 665 film.

Initial water content was determined by weighing freshly harvested fruits, drying them in an oven for 5 days at $55 \mathrm{C}$, then reweighing them. Fruits were weighed again after $24 \mathrm{~h}$, and if no weight change occurred, dry weight was recorded. Thirty-six fruits each of 'Keystone' and 'NuMex R Naky' were divided into 12 subgroups, and 90 'Santa Fe Grande' fruit were divided into nine subgroups. Surface area was estimated by covering six fresh peppers of each cultivar with graph paper and carefully cutting the paper to match the surface area. Each fruit was measured twice. Fruit volume was determined by immersing six peppers of each cultivar in a known volume of water and measuring the displacement. SA: V ratio was then calculated.

Cuticle weight was determined with enzymatically isolated fruit cuticles. A 2-cm-diameter disk from 24 fruits each of 'Keystone' and 'NuMex R Naky' and a 1.5-cm-diameter disk from 29 'Santa Fe Grande' fruits were removed using a cork borer. The cuticle was isolated enzymatically using $5 \%$ pectinase plus $0.2 \%$ cellulase at $\mathrm{pH} 4.0$ buffered with dibasic sodium phosphate-citric acid (Leon and Bukovac, 1978). Disks were incubated 12 days, and the enzyme solution was renewed every third day. Cuticles were separated from disks by gentle agitation with distilled water, thoroughly rinsed, air dried, and weighed. Three disks from each cultivar were examined with light microscopy to assure freedom from cellular debris. Data were expressed as cuticle weight per unit area (in milligrams per square centimeter).

Epicuticular waxes were removed by rinsing the outer surface of excised fruit for $5 \mathrm{sec}$ four successive times in $80-\mathrm{ml}$ portions of chloroform. Washings from 250 disks of each cultivar were evaporated to dryness at 40C, and the wax weighed (Corey et al., 1988). Data were expressed as weight per unit area (in micrograms per square centimeter).

Data for percent weight loss were analyzed as a split plot in time for each cultivar. Analysis shows significant effects of temperature, days in storage, and a temperature $\times$ days in storage interaction. Regression equations to estimate percent weight loss for each cultivar over time at each storage temperature were

Table 1. Regression equations for percent weight loss for three pepper cultivars stored at 8,14 , or $20 \mathrm{C}$ for

\begin{tabular}{lccr}
\hline \hline & $\begin{array}{c}\text { Storage } \\
\text { temp } \\
\text { Cultivar }\end{array}$ & $\begin{array}{c}\text { Regression } \\
\text { equation } \\
(\% \text { wt loss/kPa }=)^{2}\end{array}$ & $r^{{ }^{y}}$ \\
\hline Keystone & 8 & $0.43+1.49$ (day) & 0.999 \\
NuMex R Naky & 8 & $0.27+2.33$ (day) & 0.999 \\
Santa Fe Grande & 8 & $0.51+3.94$ (day) & 0.999 \\
Keystone & 14 & $4.13+7.91$ (day) & 0.999 \\
NuMex R Naky & 14 & $5.45+13.60$ (day) & 0.999 \\
Santa Fe Grande & 14 & $17.85+13.43$ (day) & 0.998 \\
Keystone & 20 & $5.48+6.62$ (day) & 0.999 \\
NuMex R Naky & 20 & $7.91+11.21$ (day) & 0.998 \\
Santa Fe Grande & 20 & $14.54+10.12$ (day) & 0.997 \\
\hline
\end{tabular}

$\overline{2}$ Regressionslopesfor'Keystone', 'NuMex R Naky', and 'Santa Fe Grande' differ significantly from each other at $P \leq 0.01$ at each storage temperature and between storage temperatures. 
developed using stepwise linear regression procedure of the Statistical Analysis System (SAS Institute, 1982). Differences between equations were determined using a $t$ test. Data for initial water content, surface area, SA: V ratio, and cuticle weight were subjected to analysis of variance. Treatment means were separated with LSD procedure. linearly with storage time for all cultivars at each storage temperature (Table 1). Regression slopes for cultivars were different $(P \leq$ $0.01)$ at each temperature, indicating cultivar differences in water-loss rates. The water-loss rate at $14 \mathrm{C}$ was 5.3-,5.8-, and 3.4-fold greater for 'Keystone', 'NuMex R Naky', and 'Santa Fe Grande', respectively, compared to fruits stored at $8 \mathrm{C}$. The water-loss rate at $20 \mathrm{C}$ was $16 \%, 18 \%$, and $25 \%$ less for 'Keystone', 'NuMex R N\&y', and 'Santa Fe Grande', respectively, compared to fruits stored at $14 \mathrm{C}$.

Water loss occurs by diffusion through the fruit cuticle (Salisbury and Ross, 1985) and, in some species, particularly tomato, through the stem scar (Cameron and Yang, 1982). The stem remained attached to the fruit in these studies, but the cut stem was not sealed. Since preliminary studies (data not presented) showed that sealing the cut stem had no effect water-loss rate likely is associated with the cuticle, fruit physical characteristics, or both.

Differences in fruit stomata number, size, or function account for water-loss rate differences in some plant organs. However, SEM studies showed no fruit stomata in the three cultivars (data not presented); therefore, other physical characteristics must account for differences in water-loss rates.

Fruit physical attributes (initial water content, surface area, SA: V ratio, cuticle weight) differed $(P \leq 0.01)$ for the three cultivars (Table $2)$. Postharvest water-loss rate was significantly correlated with fruit surface area, SA: $\mathrm{V}$, and amount of epicuticular wax at all three temperatures (Table 3), but with initial water content and cuticle weight only at 14 and 20C.
Postharvest weight (water) loss increased on water-loss rate, the basis for differences in

Initial fruit water content may affect the water-loss rate. Fruit with a lower water content would have a smaller VPD (Kays, 1991) and may, therefore, lose water at a slower rate than fruit with a higher water content. However, cultivar differences in initial water content (Table 2) were small and would not be expected to affect postharvest storage. The positive correlation between water-loss rate and initial water content at 14 and 20C (Table 3 ) is not of practical importance. While initial water content may affect water-loss rate, it is not the primary controlling factor.

The rate of postharvest water loss is controlled by the rate of movement of water to the fruit surface (diffusion) and the rate of transpiration from the surface. Greater surface (diffusional) area should result in a higher waterloss rate if cuticular permeability is constant. However, water loss rate was inversely related to surface area (Table 3). Therefore, there must be differences in cuticular water permeability among cultivars, and for these three cultivars, the fruit with smaller surface areas ('NuMex R Naky' and 'Santa Fe Grande') must have higher cuticular water permeability.

SA: $\mathrm{V}$ ratio maybe a better indicator than surface area of water-loss rate (Sastry et al., 1978; Wills et al., 1981 b). A high ratio means greater diffusional area per water-saturated volume and should translate into greater water loss. A positive correlation was observed for fruit at all storage temperatures (Table 3 ). The correlation between water-loss rate and SA: V ratio at each temperature indicates that temperatures between 8 and 20C did not significantly alter cuticular permeability; however, the lower correlation with increasing temperature suggests some change with increasing temperature, at least when VPD is unequal.

The cuticle is the prime barrier to waterloss and, therefore, may significantly affect postharvest water-loss rate. Cuticle components that may affect water-loss rate include cuticle thickness, cuticular chemistry (Schönherr, 1976; Schönherr and Schmidt.

Table 2. Quantification of selected physical attributes of three pepper cultivars at harvest.

\begin{tabular}{|c|c|c|c|c|c|}
\hline Cultivar & $\begin{array}{c}\text { Initial } \\
\text { water } \\
\text { content } \\
(\%)\end{array}$ & $\begin{array}{c}\text { Surface } \\
\text { area } \\
\left(\mathrm{cm}^{2}\right)\end{array}$ & $\begin{array}{l}\text { Surface : } \\
\text { volume } \\
\text { ratio }\end{array}$ & $\begin{array}{c}\text { Cuticle } \\
\text { wt } \\
\left(\mathrm{mg}^{\circ} \mathrm{cm}^{-2}\right)\end{array}$ & $\begin{array}{c}\text { Epicuticular } \\
\text { wax } \\
\left(\mu \mathrm{g} \cdot \mathrm{cm}^{-2}\right)\end{array}$ \\
\hline Keystone & $92.1 \mathrm{a}^{\mathrm{x}}$ & $553 \mathrm{a}$ & $0.88 \mathrm{c}$ & $1.8 \mathrm{c}$ & $113 a$ \\
\hline NuMex R Naky & $90.6 \mathrm{~b}$ & $340 \mathrm{~b}$ & $1.78 \mathrm{~b}$ & $4.4 \mathrm{a}$ & $76.4 \mathrm{~b}$ \\
\hline Santa Fe Grande & $92.0 \mathrm{a}$ & $270 \mathrm{c}$ & $2.77 \mathrm{a}$ & $2.4 \mathrm{~b}$ & $55.5 \mathrm{~b}$ \\
\hline
\end{tabular}

${ }^{2}$ Means within a column followed by different letters are significantly different at $P \leq 0.01$ with LSD procedure.

Table 3. Correlations between postharvest water-loss rate and physical attributes for pepper fruits stored at 8,14 , or $20 \mathrm{C}$ for 14 days.

\begin{tabular}{lccr}
\hline & & Storage temp $\left({ }^{\circ} \mathrm{C}\right)$ & \\
\cline { 2 - 4 } Attribute & 8 & Correlation coefficient & 20 \\
\hline & & -0.677 & -0.777 \\
Initial water content & $0.102^{2}$ & -0.901 & -0.831 \\
Fruit surface area & -0.849 & 0.799 & 0.705 \\
Surface : volume ratio & 0.927 & 0.659 & 0.828 \\
Cuticle weight $/ \mathrm{cm}^{2}$ & 0.044 & -0.866 & -0.727 \\
Epicuticular wax & -0.877 & &
\end{tabular}

1979), and epicuticular wax chemistry and distribution (Baker, 1974; Giese, 1975; Espelie et al., 1982). Weight per unit cuticle area cart give an estimate of relative cuticle thickness. A negative correlation between cuticle weight per square centimeter and water-loss rate would be expected for cuticles of equal permeability. No correlation between cuticle weight per square centimeter and water-loss rate was observed at $8 \mathrm{C}$, but a positive correlation was observed at 14 and 20C (Table 3). Water-loss rates at $8 \mathrm{C}$ were relatively low, and the role of cuticular permeability would be minimal. Water-loss rates were maximum at 14 and 20C and positively correlated with cuticle weight per square centimeter (relative thickness). Thus, as cuticle weight per square centimeter increased, water-loss rate increased, suggesting decreased resistance to water movement. Since differences in cuticle weight per square centimeter arise from different cultivars, the cultivars must differ in cuticular water permeability. Apparent cuticular permeability coefficients (in-meters per second) for each cultivar at each storage temperature were between $2.11 \times 10^{-10}$ ('Keystone', 8C) and $3.02 \times 10^{-9}$ ('Santa Fe Grande', 20C), with 'Santa Fe Grande' > 'NuMex R Naky' > 'Keystone'. The differences may be related to cuticle chemistry, epicuticular wax, or both.

Epicuticular wax quantity is often inversely related to water loss (Wills et al., $198 \mathrm{lb}$ ). In our studies, water-loss rates and epicuticular wax content were negatively correlated at all storage temperatures, suggesting epicuticular wax content is an important cuticular component regulating water loss. It must be noted that epicuticular wax content can be highly variable and influenced by environmental factors (Baker, 1974; Hunt and Baker, 1982).

Epicuticular wax structure and distribution may influence water loss (Kolattukudy, 1980; Schönherr, 1976; Wills et al., 1981 b). Uniform coverage with nonporous epicuticular wax structures would reduce water-loss rates more effectively than nonuniform coverage and porous structures (Chambers and Possingham, 1963). SEM results showed similar epicuticular wax morphology for all three cultivars (data not shown). No distinct differences related to water-loss rates were observed.

Our results suggest SA: V ratio and epicuticular wax quantity of pepper fruits are related to postharvest water-loss rates and, therefore, may help predict fruit longevity. Understanding the relationships between water-loss rate and these characteristics may help screen cultivars for relative postharvest storage and shipping suitability.

\section{Literature Cited}

Albrigo, L.G. 1972. Distribution of stomata and epicuticular wax on oranges as related to stem and rind breakdown and water loss. J. Amer. Soc. Hort. Sci. 97:220-223.

Baker, E.A. 1974. The influence of environment on leafwaxdevelopmentin Brassica oleracea var. gemmifera. New Phytol. 73:955-966.

Ben-Yehoshua,S.1987.Transpiration,waterstress, 
(cd.). Postharvest physiology of vegetables. Marcel Dekker, New York.

Bosland, P.W., A.L. Bailey, and D.J. Cotter. 1991. Growing chiles in New Mexico. New Mexico State Univ. Ext. Circ. 530.

Cameron, A.C. and S.F. Yang. 1982. A simple method for determination of resistance to gas diffusion in plant organs. Plant Physiol. 70:2123.

Chambers, D.C. and J.V. Possingham. 1963. Studies of the fine structure of the wax layer of sultana grapes. Austral. J. Biol. Sci. 16:818825

Corey, K.A., D.V. Schlimme, and N.A. Chaney. 1988. Changes in epicuticular wax on watermelon fruits during ripening. HortScience 24:730-731.

Espelie, K. E., S.C. Carvalho, and P.E. Kolattukudy. 1982. Effects of commercial waxing on the content and composition of total wax and on diffusion resistance of 'Delicious' apples. HortScience 17:779-780.

Giese, B.N. 1975. Effects of light and temperature on the composition of epicuticular wax of barley leaves. Phytochemistry 14:921-929.

Hunt, G.M. and E.A. Baker. 1982. Developmental and environmental variations in plant epicuticular waxes Some effects on penetration of naphthyl acetic acid, p. 279-292. In: D.F. Cutler, K.L. Alvin, and C.E. Price (eds.). The plant cuticle. Academic, London.

Kays, S.J. 1991. Postharvest physiology of perishable plant products. Van Nostrand Reinhold, New York, N.Y.

Kolattukudy, P.E. 1980. Cutin, suberin and waxes, p. 571-645. In: P.K. Stumpf (cd.). The biochemistry of plants. vol. IV. Academic, New York.

Leon, J.M. and M.J. Bukovac. 1978. Cuticle development and surface morphology of olive leaves with reference to penetration of foliarapplied chemicals. J. Amer. Soc. Hort. Sci. 103:465-472.

Lownds, N.K. and P.W. Boslaud. 1988. Studies on postharvest storage of pepper fruits. HortScience 23:71. (Abstr.)

Robinson, J. E., K.M. Browne, and W.G. Burton. 1975. Storage characteristics of some vegetables and soft fruits. Ann. Applied Biol. 81:399-408.

Ryan, A.L. and W.J. Lipton. 1972. Handling, transportation and storage of fruits and vegetables. vol. 1. AVI, Westport, Conn. p. 11-14.

Salisbury, F.B. and C.W. Ross. 1985. Plant physiology. Wadsworth, Belmont, Calif.

SAS Institute. 1982. SAS user's guide: Statistics. SAS Institute, Cary, N.C.

Sastry, S. K., C.D. Baird, and D.E. Buffington. 1978.
Transpiration rates of certain fruits and vegetables. Amer. Sot. Heating, Refrigerating, Airconditioning Eng. Trans. 84:237-255.

Schönherr, J. 1976. Water permeability of isolated cuticular membranes: The effect of cuticular waxes on diffusion of water. Planta 131: 159164.

Schönherr, J. and H.W. Schmidt. 1979. Water permeability of plant cuticles: Dependence of permeability coefficients of cuticular transpiration on vapor pressure saturation deficit. Planta 144:391-400.

Showalter, R.K. 1973. Factors affecting pepper firmness. Proc. Fla. State Hort. Soc. 86:230-232.

Watada, A.E., S.D. Kim, K.S. Kim, and T.C. Harris. 1987. Quality of green beans, bell peppers and spinach stored in polyethylene bags. J. Food Sci. 52:1637-1641.

Wills, R. B. H., T.H. Lee, D. Graham, W.B. McGlasson, and E.G. Hall. 1981a. Physiology and biochemistry, p. 17-37. In: Postharvest An introduction to the physiology and handling of fruit and vegetables. AVI, Westport, Conn

Wills, R. B. H., T.H. Lee, D. Graham, W.B. McGlasson, and E.G. Hall. 198 lb. Water loss and humidity, p. 52-59. In: Postharvest: An introduction to the physiology and handling of fruit and vegetables. AVI, Westport, Conn. 